\title{
Effects of a Two-Month Training Period on Soldiers' General Health, Social Physique Anxiety, and Body Mass Index
}

\author{
Jalal Dehghanizade ${ }^{1, *}$ and Farshad Najafipour ${ }^{2}$ \\ ${ }_{1}^{1}$ Department of Physical Education and Sport Science, Urmia University, Urmia, IR Iran \\ ${ }^{2}$ Department of Epidemiology, AJA University of Medical Sciences, Tehran, IR Iran \\ *Corresponding author. Jalal Dehghanizade, Department of Physical Education and Sport Science,Urmia University, Urmia, IR Iran. Tel:+98-9139704369, E-mail: jalal.dehghanizade@yahoo.com
}

Received 2015 October 13; Revised 2015 December 12; Accepted 2015 December 12.

\begin{abstract}
Background: Changes in the environment and living conditions are associated with changes in physical and cognitive functions. Objectives: The aim of this study was to examine the effects of a two-month military service period on soldiers' general health, social physique anxiety, and body mass index.

Materials and Methods: The sample included all soldiers in Isfahan's army garrison training period. A28-item questionnaire on general health, a social physique anxiety questionnaire (Hart et al. 1989) that measured the social physical anxiety and the ratio of weight to the height square calculating body mass index.

Results: The results of the paired t-test showed that there were significant differences in pre-test and post-test scores on the general health aspects of anxiety and social physique anxiety and there were no significant differences in other aspects of soldiers' general health and body mass index. This suggests that the two-month training period affects only the variables of anxiety (anxiety, insomnia, and social physique anxiety).

Conclusions: The findings showed that the military training period can significantly affect anxiety, but it cannot affect the health and body mass index.
\end{abstract}

Keywords: General Health, Social Physique Anxiety, Body Mass Index, Armed Forces

\section{Background}

A soldier is the accredited centerpiece of an army's warfighting system, and the army's success mainly depends on the physical and mental status of soldiers. The difficulty, speed, and the deadliness of modern warfare mean that even tiny mental slips may have threatening outcomes. Belief and opinion, psychomotor efficiency, mood and cooperation, and cognitive status are all discriminating origins of soldier performance. These origins in the military service have been customarily appraised by viewing or as pure results, like a task or role fulfillment (1).

Starting forceful military service at the age of 18 years old is stressful for adolescent soldiers, and there is a comprehensive report on the record of mental illnesses in terms of their diagnosis, treatment, and symptomatology at the same time (2-4). The slur of mental disease disheartens young soldiers from reporting signs of disease and from getting help (5). This extra intricate recognition and assessment of soldiers prepares risky soldiers for committing suicide and forbidding the proper remedial interpositions offering.

More than 33\% of the Iranian population is composed of young people (18 to 24 years) who are joining the military service to guard the country in accordance with the country's regulations. This odd stage of life is accompanied by a diversity of stressors, such as household leave, support systems, various eating habits, changes in sleeping habits, limited freedom, particular and imposed regularity, changing place and situation, the anxiety of dealing with new events, difficulty and incompatibility with superiors and peers, leading to low self-esteem in solving problems (6). In fact, weakness to confront and solve problems sufficiently can lead to problems being advented as emotional disturbances, increased sensitivity to external stimuli, anxiety, distress, mood changes, and depression (7). In the military area, accommodation is generally needed at two levels, and while trying to make these accommodations, certain individuals experience emotional upheaval. The first stage of adjustment solders face is in the instructional environment, making them adapt their lifestyle from a non-military to a military one.

The second stage is becoming adjusted to the contradictory conditions of combat or the risk of war (2). Reportedly, people who are emotionally competent facilitate confronting challenges expanding their mental health (8). Farsi and Ebadi (2006) indicated that $14.8 \%$ of soldiers reported stress, $31.3 \%$ anxiety, and $18.2 \%$ depression. In addition, income, educational environment, previous job experience, a history of taking pills and medicine, and

Copyright ( ) 2016, AJA University of Medical Sciences. This is an open-access article distributed under the terms of the Creative Commons Attribution-NonCommercial 4.0 International License (http://creativecommons.org/licenses/by-nc/4.0/) which permits copy and redistribute the material just in noncommercial usages, provided the original work is properly cited. 
family illness were found to be associated with emotional reactions (9). Moreover, $57.80 \%$ of soldiers in Tehran seemed to be upset of mental disorder and a meaningful correlation was found between mental disorders and physical inactivity, history of self-mutilation, and escaping from the military service (10). Taghva et al. (2014) reported that depressive symptoms were the most common problem among soldiers, with anxiety and social dysfunction coming in second and third, respectively (11). Hence, soldiers' physical and mental health is particularly important. Some variables, including general health, social physique anxiety (SPA), and body mass index (BMI) evaluations, are used to assess the soldiers' physical and mental health due importance the interaction of physical and cognitive function, enhancing social, military, and defense powers.

There are many studies showing a U-shaped relationship between BMI and psychological and mental status, including depression, mental health disorders, and severe mental tension (12). A study by Norman and Fraser (13) confirmed the relationship between general health and BMI. This study has shown that a clear U-shaped relationship between BMI and health has been found when controlling the demographic levels of individual, socioeconomic, and health-related behavior variables and area deprivation.

Participating in a conscription period can be a stressful experience for some young people (14). Aside from worrying about a lack of skill and capability to participate in the various military programs and physical activities being offered during conscription classes (14), there is a conflux of social and developmental agents increasing soldiers' feelings about performing and/or showing their bodies in front of others (15). Some of these factors include an amplified sense of social self-consciousness, variation in maturation rates, the powerful need for peer acceptance, and the significance of feeling physically interested in one's self-esteem. The junction of these factors within the social background of conscription may incline soldiers to experience greater SPA, due to the perception that others assess their bodies in a negative manner (16). SPA is more likely to occur in settings like conscription where displays of competence or incompetence are made publicly and being reflected in physical performance and appearance $(14,16,17)$.

Since the connections between BMI and appearancebased social anxiety have only been mediated by body image dissatisfaction, and the model of these relationships emerged as the best-fitting model compared to a plausible alternative model, and the relationship between BMI and health-related behavior has been identified (13), changes in each variable may cause changes in other variables.

Since various physical and cognitive programs during military service is compulsory for all young men, it is likely that general health and subsequently SPA and BMI is changed. Thus, the question regarding general health involves what changes for young people during this period. Does the SPA level change during the course ? Does the conscription period affect their BMI? And if so, will these changes be positive or negative? The obtained findings could help in the design of programs for young people.

\section{Objectives}

The aim of this study was to examine the effects of a twomonth military service period on the general health, SPA, and BMI of soldiers.

\section{Materials and Methods}

The design of the study was semi-experimental, and the statistical population included all the soldiers in the training period of Isfahan army garrison. A sample of 210 soldiers was selected, and due to factors such as illness, escaping from the training period, and not completing the questionnaire, this number decreased to 178. The age of the subjects ranged from 22 to 27 years with an average of 24.35 years. They all had a bachelor's degree, 156 of them were single, and the rest were married. All the studied variables follow a normal distribution (Table 1).

The general health questionnaire (GHQ-28) (18) and the social physique anxiety scale (SPAS) (16) were used to assess the general health and SPA of soldiers.

\subsection{GHQ-28}

The 28-item GHQ includes 4 subscales: somatic symptoms, social dysfunction, anxiety and insomnia, and severe depression. The reliability coefficients were calculated for test-retest (0.70), split-half (0.93), and Cronbach's alpha (0.90). Through the middlesex hospital questionnaire (MHQ), the concurrent validity of the questionnaire was reported as 0.005 . In addition, the subscale-total correlations were between 0.72 and 0.87 . Thus, the results indicate that the GHQ-28 is a valid scale to be used in Iran (19).

\begin{tabular}{lc}
\hline Table 1. Descriptive Statistics & \\
\hline Variables & Mean \\
\hline Age, $\mathbf{y}$ & $24.35 \pm 1.56$ \\
Height, $\mathbf{m}$ & $1.78 \pm 0.077$ \\
Pre-weight, kg & $74.73 \pm 11.46$ \\
Post-weight, kg & $74.68 \pm 11.24$ \\
\hline
\end{tabular}

${ }^{\mathrm{a}}$ Data are expressed as mean $\pm \mathrm{SD}$.

\subsection{SPAS}

The degree in which soldiers felt anxious about the appearance of their body was measured with 12 items from the social physique anxiety scale (16). The subjects specified their answers to each item on a Likert scale ranging from 1 (not at all) to 5 (very much). Their scores ranged from 7 to 49. The higher the score, the higher the socialphysical anxiety (SPA). The time reliability of this test has been reported to be 0.94 , according to the retesting method. Yousefi et al. (2009) have reported the elemental reliability and validity of this scale in Iranian student population (19). According to the results of this basic analysis, which was done using the data acquired from 237 students of the university of Kermanshah (108 girls 
and 129 boys), the elemental structure of this scale is welldepicted in both genders. Calculating Cronbach's alpha for all items indicated that the internal stability of the test was 0.85 for female students and 0.81 for the male ones, which is considered acceptable (20).

\subsection{BMI}

This continuous variable was calculated based on selfreported weight $(\mathrm{kg})$ divided by self-reported height (meters) squared.

\section{Results}

The Kolmogorov-Smirnov test was used to assess the normality of data; results confirmed the normal distribution of scores in the pretest $(\mathrm{P}>0.05)$. Thus, it can be used in parametric tests. Differences between the pre- and post-test means were using a t-test (Paired-samples) for all variables (Table 2).

A paired t-test indicated significantly reduced anxiety and insomnia $(\mathrm{t}=2.255, \mathrm{P}=0.025)$ and SPA $(\mathrm{t}=3.983, \mathrm{P}$ $=0.001$ ) between pre- and post-tests. However, it did not show a significant difference in other variables, including somatic symptoms $(t=0.428, P=0.669)$, social dysfunction $(t=1.181, P=0.239)$, severe depression $(t=1.491$, $\mathrm{P}=0.138)$, general health $(\mathrm{t}=1.76, \mathrm{P}=0.08)$, and $\mathrm{BMI}(\mathrm{t}=$ $1.605, \mathrm{P}=0.11)$. In other words, the conscription period affected soldiers' anxiety. (Figure 1)

Table 2. Comparison of the Research Variables Before and After the Military Service Period

\begin{tabular}{lcccc}
\hline Variables & Pre-Mean $^{\mathrm{a}}$ & Post-Mean $^{\mathrm{a}}$ & $\mathrm{T}$ & P Value \\
\hline Somatic symptoms & $7.06 \pm 5.2$ & $7.07 \pm 5.11$ & 0.428 & .669 \\
Anxiety and insomnia & $7.94 \pm 5.26$ & $7.79 \pm 4.91$ & 2.255 & .025 \\
Social dysfunction & $8.82 \pm 4.15$ & $8.76 \pm 3.99$ & 1.181 & .239 \\
Severe depression & $4.76 \pm 5.72$ & $4.62 \pm 5.33$ & 1.491 & .138 \\
General health & $28.58 \pm 17.95$ & $28.25 \pm 16.91$ & 1.76 & .08 \\
Social physique anxiety & $23.88 \pm 7.54$ & $23.16 \pm 6.22$ & 3.893 & .001 \\
BMI, kg/m & $23.47 \pm 3.01$ & $23.45 \pm 2.97$ & 1.605 & .11 \\
\hline
\end{tabular}

${ }^{\mathrm{a}}$ Data are expressed as mean $\pm \mathrm{SD}$.

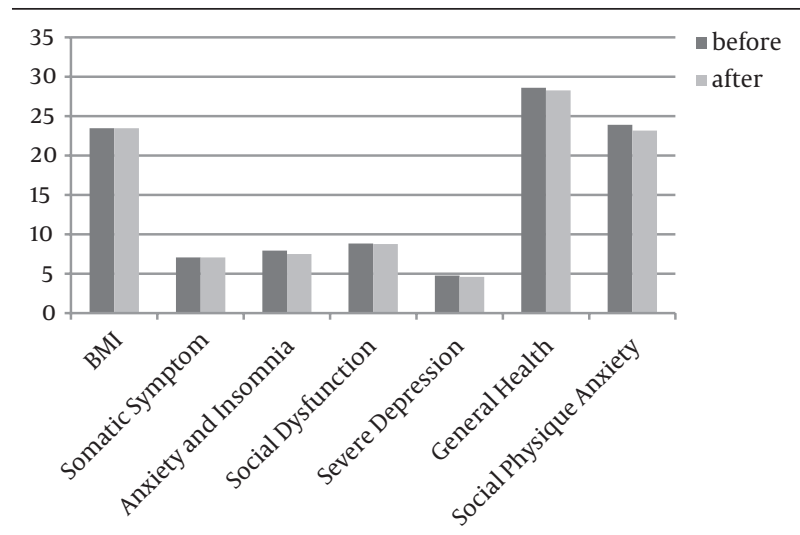

Figure 1. Trend of Changes in Variables Before and After the Military Service Period

\section{Discussion}

This study examined the impact of the initial military period on the physical and mental health of soldiers. Somatic symptoms, social dysfunction, anxiety and insomnia, severe depression, SPA, and BMI were studied. The results showed that the military period's effect on anxiety and other health fields among youth remains unchanged. By the beginning of military service, a young person faces changes in lifestyle. Entering into the military environment requires a change in behavior. In other words, the person must have the ability to adapt to different situations and interact with new people to achieve optimal performance.

The results showed that only the anxiety of the general health dimensions of the armed forces at the end of the period showed a significant decrease compared to the beginning. The findings of this study are consistent with those of Khademolhoseini et al. (2009) and Fakourian et al. $(2012)(21,22)$. What is certain is that young soldiers experience stress during military service (23). This stress begins when a person is preparing for a military period, which reaches its culminating point with the separation from family and country. According to psychology estimates, when stress levels increase, stress transforms into anxiety and aggression (24). Therefore, it is probable that feeling anxious in the early days of the military is regarded as strong feeling. But continuing to live in a military environment, gaining familiarity with new peers, undertaking different responsibilities, complying with military environmental programs, and becoming accustomed and comfortable with the new environment leads to a gradual decline in the fear of facing the environment And gradually people change their mind about the military environment, consequently it leads to decline of their stress and anxiety (25). So, it is likely that at the end of the period one can show a significant reduction in the level of anxiety experienced. However, other general health aspects remain unchanged. Individuals' somatic symptoms depend more on their physical activity, which is affected by the organized programs in the environment (23). It is possible that programs and physical activities do not have sufficient intensity and duration to affect physical health. In addition, there are symptoms of depression that remain at the primary level because individuals' perceptions of being away from home and friends remain in their subconscious. In addition, sleeping and waking hours, which is one of the important factors, did not significantly change during the period. Finally, social function with regard to the specific characteristics of the military environment did not undergo significant changes that likely have not adaptation attendance in an environment with regular programs and certain social situations for young who had performed social activities without a plan and order and needs more time to adapt to conditions until before it. Totally during the two-month military service period, fear-based sense 
of separation, feelings of loneliness, and the other hand, the unclear next situation in person that it should be activities longer, continued to a soldier until the end of period and public health will have no significant changes.

In addition, according to the research findings, a significant difference was observed in the extent of social-physical anxiety before and after military service. In fact, doing activity trainings could decrease social-physical anxiety in young soldiers. Given the conducted studies, the fear of participating in military communities is one of the main reasons for this problem due to them being considered as threats and being laughed at by other members of society. One of the major reasons for this avoidance is social-physical anxiety in soldiers (26). As mentioned, SPA is a social psychological variable extracted from theories of impression management and self-presentation that reflects an individual's perceived anguish or concern with the exhibition of his/her physique in situations in which others are perceived to be evaluating him/her. This variable is significant because it has been shown to be relevant to behavioral factors and have a psychological relationship with health. For instance, SPA is related to body image (27), physical self-esteem (28), eating attitudes (24), dissatisfaction with appearance and weight (29), and motivation to avoid health-related behaviors, such as motor activity (30). In addition, there is a substantial body of research that has examined the structure of SPA and the contextual factors that give rise to this variable $(25,31)$. One of these contextual factors is participating in a new and different environment such as the military environment.

Self-determination theory defines motivation regulations as the reason individuals engage in a specific behavior. Organismic integration theory, a sub-theory of self-determination theory, details how these distinct regulations range from being completely autonomous or emanating from within the individual being completely controlling or originating from a source outside of the individual (32). The independent regulations consist of intrinsic motivation (e.g., participating in the military because it is thrilling), integrated regulation (e.g., participating in the military because it is consonant with soldiers' life goals), and identified regulation (e.g., participating in the military because it is worthy or important to the youth). The controlling regulations include intrinsic regulation (e.g., participating in the military to avoid embarrassment or social approval) and external regulation (e.g., participating in the military to satisfy an external contingency like avoiding a reprimand or improving one's social situation) (24). Thus, these regulations not only increase cognitive anxiety, but also enhance SPA due to Peoples or soldiers . Of course, this increase in the initial days of the military period reaches its peak and anxiety levels decrease over time as they adapt to their conditions. Therefore, we can say that SPA is reduced by one's presence in a military environment and observation of peers.
Ultimately, the results showed that there was no significant difference in soldiers' BMI at the beginning and the end of the period, although this index at the end of the period was associated with a decrease in the average. These results are consistent with research by Fakourian et al. (2012) (22). In their study, they examined the impacts of a long military exercise on fitness, BMI, mental health, and mood and found no significant effect of exercise on BMI. In fact, factors such as the intensity, duration, and type of physical exercise and regular physical activity can affect the change in BMI. In the present study, both military programs and sports programs and physical education activities do not seem to have sufficient intensity and duration to change the BMI of soldiers. The exercises and activities affecting the BMI should be based on $\mathrm{Vo}_{2 \max }$ and the maximum heart rate and be programmed individually (33). In addition, the BMI is a variable that interacts with several factors, including heredity, physical activity, inflammation, sleep and circadian rhythm, stress, and meals, and cannot be explained only by one factor. Many studies, however, either combine the underweight with the normal weight category or do not report or highlight results from the underweight group (13). In other words, both underweight and overweight categories are associated with a healthy lifestyle (26). Thus, weight changes (severe increase or decrease) may cause mental and physical disorders in which this possibility increases in stressful environments. The BMI of the sample at the beginning and end of the training period was within the normal range, and according to the U-shaped model, it is likely that health has not been significantly affected as well.

U-shaped relationships between BMI categories and health are noted in previous research and presented in the results, but without emphasis (12). Controlling for socioeconomic, health behavior, and deprivation variables compared with persons of normal weight, the significantly increased likelihoods of persons to report poor general health for both underweight and obese BMI categories and a slight but significant increase for persons who are overweight were found. The findings of self-reported health are consistent with previous research demonstrating a clear U-shape between BMI and depression (15) and self-rated health (26). Thus, many factors need to be monitored and only by diet and physical activity cannot be concluded including different individual experiences. Therefore, in future studies, more variables and more accurate measures should be considered.

Although previous researchers have pointed out the influence of the military period on mental health (11), this study showed no effect other than anxiety. This study showed no significant changes in depression, social dysfunction, and somatic symptoms at the end of the training course.

In summary, these findings suggest that the military service period does not have a significant impact on health indicators (with the exception of anxiety). There- 
fore, it is necessary for military service programs to be designed and executed to help support youth's health promotion. One of the main strategies is to increase the hours of physical activity, as this is likely to optimize soldiers' physical performance and BMI.

\section{Acknowledgments}

We thank Mr. Akbar Ghasemi and all the soldiers who participated in this study for their sincere support.

\section{Footnotes}

Authors' Contribution:Study conception and design: Jalal Dehghanizade, and Farshad Najafipour; acquisition of data: Jalal Dehghanizade; analysis and interpretation of data: Jalal Dehghanizade; drafting of manuscript: Jalal Dehghanizade, Farshad Najafipour; critical revision: Farshad Najafipour.

Funding/Support:This research supported by Physical education of the Armed Forces.

\section{References}

1. Letz R. Continuing challenges for computer-based neuropsychological tests. Neurotoxicology. 2003;24(4-5):479-89. doi: 10.1016/ S0161-813X(03)00047-0. [PubMed: 12900 061]

2. Friedl KE, Grate SJ, Proctor SP, Ness JW, Lukey BJ, Kane RL. Army research needs for automated neuropsychological tests: monitoring soldier health and performance status. Arch Clin Neuropsychol. 2007;22 Suppl 1:S7-14. doi: 10.1016/j.acn.2006.10.002. [PubMed: 17127031]

3. Greene-Shortridge TM, Britt TW, Castro CA. The stigma of mental health problems in the military. Mil Med. 2007;172(2):157-61. [PubMed: 17357770]

4. Yacobi A, Fruchter E, Mann JJ, Shelef L. Differentiating Army suicide attempters from psychologically treated and untreated soldiers: a demographic, psychological and stress-reaction characterization. J Affect Disord. 2013;150(2):300-5. doi: 10.1016/j. jad.2013.04.009. [PubMed: 23668905]

5. Kim PY, Thomas JL, Wilk JE, Castro CA, Hoge CW. Stigma, barriers to care, and use of mental health services among active duty and National Guard soldiers after combat. Psychiatr Serv. 2010;61(6):582-8. doi:10.1176/appi.ps.61.6.582. [PubMed:20513681]

6. Florkowski A, Gruszczynski W, Wawrzyniak Z. Evaluation of psychopathological factors and origins of suicides committed by soldiers, 1989 to 1998. Mil Med. 2001;166(1):44-7. [PubMed: 11197097]

7. King LA, Emmons RA. Conflict over emotional expression: psychological and physical correlates. J Pers Soc Psychol. 1990;58(5):864-77. [PubMed: 2348373]

8. Goleman D. Emotional intelligence. New York: Bantam; 1995. Available from: http://www.danielgoleman.info/topics/emotionalintelligence/.

9. Farsi ZJM, Ebadi AA. Study of the mental health status of soldiers referring to an outpatient military clinic inTehran.J Mil Univ Med Sci. 2006;4(15):923-30.

10. Revah-Levy A, Speranza M, Barry C, Hassler C, Gasquet I, Moro MR, et al. Association between Body Mass Index and depression: the "fat and jolly" hypothesis for adolescents girls. BMC Public Health. 2011;11:649. doi:10.1186/1471-2458-11-649. [PubMed: 21846386]

11. Taghva A, Azizi M, Rajabian MH, Khademi M, Omid A, Donyavi V, et al. Average Military Service Length and Soldiers' General Health. J Arch Mil Med. 2014;2(4):20604.

12. Minet Kinge J, Morris S. Socioeconomic variation in the impact of obesity on health-related quality of life. Soc Sci Med.
2010;71(10):1864-71. doi: 10.1016/j.socscimed.2010.09.001. [PubMed: 20932623]

13. Norman P, Fraser L. Self-reported general health and Body Mass Index: a U-shaped relationship? Public Health. 2013;127(10):93845. doi:10.1016/j.puhe.2013.07.003. [PubMed:24112442]

14. Smith AL. Peer relationships in physical activity contexts: a road less traveled in youth sport and exercise psychology research. Psychol Sport Exerc. 2003;4(1):25-39. doi: 10.1016/s14690292(02)00015-8.

15. Hart EA, Leary MR, Rejeski WJ. The measurement of social physique anxiety. J Sport Exerc Psychol.1989;11(1):94-104.

16. Crombie PA, Brunet J, Sabiston CM. Stop Staring! J Phys Educ Recreat Dance. 2011;82(2):39-43. doi:10.1080/07303084.2011.10598581.

17. Goldberg DP, Hillier VF. A scaled version of the General Health Questionnaire. Psychol Med. 2009;9(01):139. doi: 10.1017| s0033291700021644. [PubMed: 424481]

18. Taghavi SMR. Validity and reliability of the general health questionnaire (ghq-28) in college students of shiraz universi1y. J Psychol. 2002;5(4):381-98.

19. Yousefi B, Hassani Z, Shokri O. Reliability and factor validity of the 7-item social physique anxiety scale (SPAS-7) among university students in Iran. World J Sport Sci. 2009;2(3):201-4.

20. Maleki B, Sanei S, Borhani H, Ghavami A. The Effect of military training on personality Traits in military Students. J Mil Med. 2012;13(4):195-200.

21. Khademolhoseini SM, Najafi S, Ebadi A, Naji M, Rezaee Hajiabadi $\mathrm{H}$, Asgari AR. Influence of military training period on cadet students' mental health. J Mil Med. 2009;11(2):75-9.

22. Fakourian A, Azarbaijani MA, Peeri M. Effect a period of selective military training on physical fitness, body mass index, mental health and mood in officer students. HBI J. 2012;10(1):17-27.

23. Cox AE, Ullrich-French S, Sabiston CM. Using motivation regulations in a person-centered approach to examine the link between social physique anxiety in physical education and physical activity-related outcomes in adolescents. Psychol Sport Exerc. 2013;14(4):461-7.

24. Crawford S, Eklund RC. Social physique anxiety, reasons for exercise, and attitudes toward exercise settings. J Sport Exerc Psychol. 1994;16:70.

25. Chad K, Spink KS. Body image, social physique anxiety, and tendency to develop eating disorders in female gymnasts. $J$ Appl Sport Psychol.1996;8(Suppl):S148.

26. Carlson TB. We hate gym: Student alienation from physical education.J Teach Phys Educ. 1995;14:467.

27. Kowalski NP, Crocker PR, Kowalski KC. Physical self and physical activity relationships in college women: does social physique anxiety moderate effects? Res Q Exerc Sport. 2001;72(1):55-62. doi: 10.1080/02701367.2001.10608932. [PubMed:11253320]

28. Haase AM, Prapavessis H. Social physique anxiety and eating attitudes: Moderating effects of body mass and gender. Psychol Health Med.1998;3(2):201-10. doi: 10.1080/13548509808402236.

29. Niven A, Fawkner S, Knowles AM, Henretty J, Stephenson C. Social physique anxiety and physical activity in early adolescent girls: the influence of maturation and physical activity motives. J Sports Sci. 2009;27(3):299-305. doi:10.1080/02640410802578164. [PubMed:19153865]

30. Hagger MS, Stevenson A. Social physique anxiety and physical self-esteem: gender and age effects. Psychol Health. 2010;25(1):89110. doi: 10.1080/08870440903160990. [PubMed: 20391209]

31. Ryan RM, Patrick H, Deci EL, Williams GC. Facilitating health behaviour change and its maintenance: Interventions based on self-determination theory. Eur Health Psychol. 2008;10(1):2-5.

32. Doll HA, Petersen SE, Stewart-Brown SL. Obesity and physical and emotional well-being: associations between body mass index, chronic illness, and the physical and mental components of the SF-36 questionnaire. Obes Res. 2000;8(2):160-70. doi: 10.1038/ oby.2000.17. [PubMed:10757202]

33. Kelly SJ, Daniel M, Dal Grande E, Taylor A. Mental ill-health across the continuum of body mass index. BMC Public Health. 2011;11:765. doi:10.1186/1471-2458-11-765. [PubMed: 21975214] 